\title{
Examining the Long-Haul Relationship between Primary Education and Economic Growth: Evidence from Three Populous Nations
}

\author{
Rachna Tewari (Corresponding author) \\ University of Tennessee at Martin \\ United States
}

Tel: 731-881-7196 E-mail: rtewari@utm.edu

Joey Mehlhorn

University of Tennessee at Martin

United States

Scott D. Parrott

University of Tennessee at Martin

United States

Received: August 28, 2015 Accepted: October 1, 2015 Published: November 12, 2015

doi:10.5296/ire.v4i1.8209 URL: http://dx.doi.org/10.5296/ire.v4i1.8209

\begin{abstract}
The prominence of early education as a significant source of economic growth has long been an intriguing topic among economists. The purpose of this study was to examine the relationship between primary education and GDP as a measure of economic growth in China, India, and the U.S, the top three populous nations in the world, and to investigate for plausible reasons leading to the differences observed among the mentioned countries of study. Data derived from the Education Statistics of the World Bank from 1970-2012 were subject to the ordinary least square (OLS) estimation procedure, to obtain regression coefficients as a measure of influence of the study variables on economic growth. Results revealed that for all the three study countries characterized by high populations, an increase in the number of students enrolled in primary education positively impacted economic growth. Mortality rate, primary school
\end{abstract}


graduation age population (female), population aged 0 to 14 as percentage of total population, and primary school enrollment ratio showed significant negative impacts on GDP. Marked differences were revealed for individual country regressions regarding the influence of the study variables on economic growth. Gender related differences in primary education graduating population can be attributed to varied differences in the cultural and social systems among the study countries. Both male and female primary education graduation age population showed no statistical significance on economic growth in the U.S, while for China and India the effects on economic growth were significant with clearly outlined gender related differences in primary education graduation age population. This study builds ground for further research on how the accumulation of human capital through education in these countries will impact the geographical concentration of global economic power in the future.

Keywords: China, economic growth, India, primary education, population, U.S.

\section{Introduction}

The prominence of early education as a significant source of economic growth has long been an intriguing topic among economists. Recent investigations attribute early education as a major contributor towards individual empowerment among countries witnessing rapid economic growth. According to the Global trends report (National Intelligence Council, 2012), by 2030 Asia will supersede North America and Europe combined in terms of GDP and population. A significant contributor to this growth is a rising global educated middle class, majority of which resides in the heavily populated countries of China and India. Therefore, early education emerges as an intuitive factor in the formation of human capital over time, particularly in highly populated nations in the world.

Education is considered to be an influential factor in the growth of human capital for a nation because of several associated benefits, such as reducing inequality, betterment in the quality of life of the citizens, and promoting income levels (Loening, 2005). Past macroeconomic studies have taken one of two approaches for inclusion of human capital in models of economic growth, according to Sianesi and Van Reenen (2003). These are the augmented Solow model and the theories of new growth. The augmented Solow model allows human capital to be included as an extra input in the production function (Solow, 1956). Studies based on this model however suggest that the accumulation of human capital may have only a short-term impact on the rate of growth, as the long-term growth is influenced more by progress in technological advancements (Loening, 2005; Mankiw, Romer, \& Weil, 1992). The theories of new growth suggest that long-run growth can be influenced endogenous determination through policy intervention, instead of exogenous technological change (Loening, 2005). Romer (1990) and Grossman and Helpman (1991) indicated that domestic technological progress is an outcome of the search for innovations, leading to increased productivity, in turn leading to long-run growth.

Specifically, with regard to education the results from Sala-i-Martin (2002), Easterly (2001), and Pritchett (2001) indicated a weak empirical relationship between education and growth. Loening (2005) suggested that a distinct role for different education levels' impact on economic growth can be derived within an endogenous growth framework. This concept is 
based on the premise that while primary education increases the level of cognitive skills that leads to higher productivity, post-primary education on the other hand enhances learning of novel technologies that positively contribute to knowledge production.

Barro and Sala-i-Martin (1995) evaluated the impact of initial income and few control variables on the growth rate of GDP per capita for various countries. The measures of educational attainment used in this study are average number of years of secondary and higher schooling for males and females respectively. Results indicated that male education variables together show a significant positive impact on growth, while female variables sometimes impact growth negatively. The study also suggested that the discrimination of females in formal labor markets could be a plausible interpretation for the above, or the negative sign could be an outcome of the collinearity of the education variables. Further, this study did not find any significance with regard to average years of female and male primary education. Barro (2001) further examined the relation between education and growth, and found that school quality was far more influential on growth when compared to quantity.

Among other gender related studies examining economic growth, a notable inference from Psacharopoulos (1994) indicates that in comparison to their male counterparts, investment in female education leads to positive and higher returns. Several other studies suggest economic growth benefits from gender equality especially where education is concerned. A study by Behrman et al. (1999) indicated a higher amount of effort and time on a daily basis being put into education by children of more literate mothers in India.

Recently, Barro (2013) found that the impact of female primary graduation age population showed statistical insignificance with a positive sign. Finally, Petrakis and Stamatakis (2002) conducted a smaller sample sized cross-country regression considering advanced, developed and less developed countries. The results indicated that with variations in the level of development of a country, the education and growth also varied. Primary education seemed more important in less developed countries, while higher education seems dominant in advanced countries.

The objectives of this paper are to examine the relationship between primary education, and economic growth in China, India, and the U.S, the top three populous nations in the world and to investigate for plausible reasons leading to the differences observed among the mentioned countries of study. The paper will be organized as follows. The next section discusses the empirical methodology followed by the results, conclusions and recommendations.

\section{Empirical Methodology}

The data for this study is derived from the Education Statistics of the World Bank over a period of 1970-2012 (World Bank, 2014). In total, the data had 3 cross sectional units for U.S, China, and India with a total of 129 observations. The descriptive statistics using the means procedure in SAS are presented in Table 1. 
Table 1. Descriptive statistics of education and economic growth data for the three countries of study (China, U.S, India) over a study period of 1970 to 2012

\begin{tabular}{lccccc}
\hline Variable & $\mathrm{N}$ & Mean & Std Dev & Minimum & Maximum \\
\hline LnGDP & 129 & 27.63 & 1.59 & 24.87 & 30.42 \\
Ln Grad Age Female Popn & 129 & 15.56 & 0.79 & 14.33 & 16.42 \\
Ln Grad Age Male Popn & 129 & 15.63 & 0.81 & 14.38 & 16.51 \\
Mortality rate & 129 & 63.40 & 56.78 & 7.00 & 211.00 \\
Ln Prim Edu Pupils Popn & 129 & 17.98 & 0.78 & 16.77 & 18.83 \\
School Enroll Prim (\% gross) & 129 & 103.20 & 13.22 & 78.24 & 132.34 \\
Popn ages 0-14 (\% total) & 129 & 29.30 & 7.46 & 17.98 & 41.13 \\
\hline
\end{tabular}

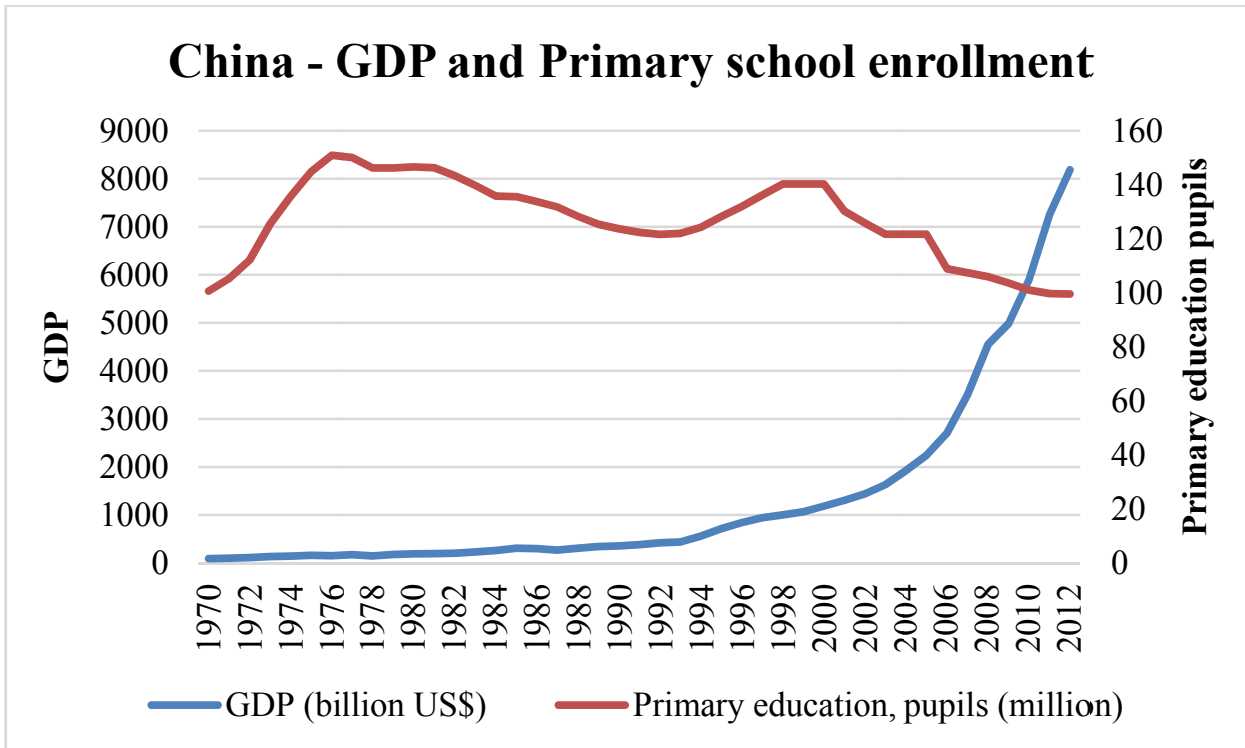

Figure 1. Movement of GDP and primary education pupil numbers from 1970-2012 in China

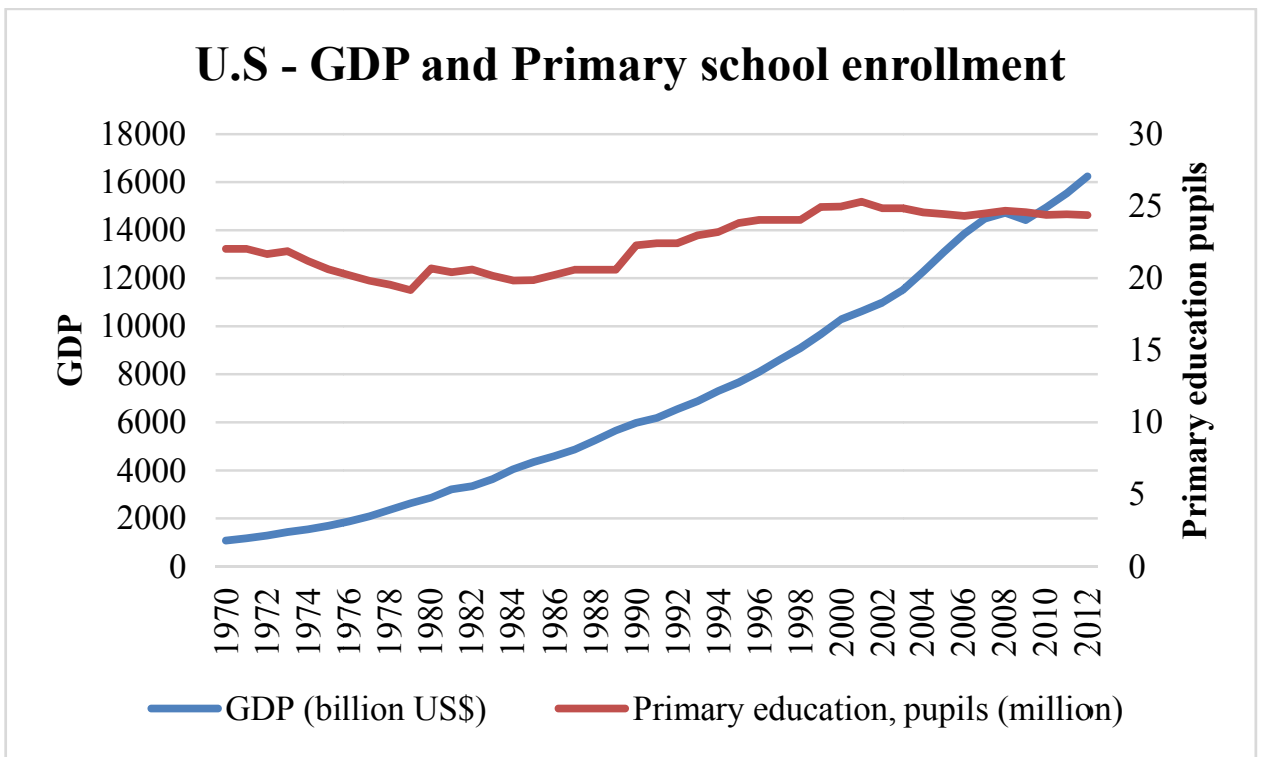

Figure 2. Movement of GDP and primary education pupil numbers from 1970-2012 in the U.S 


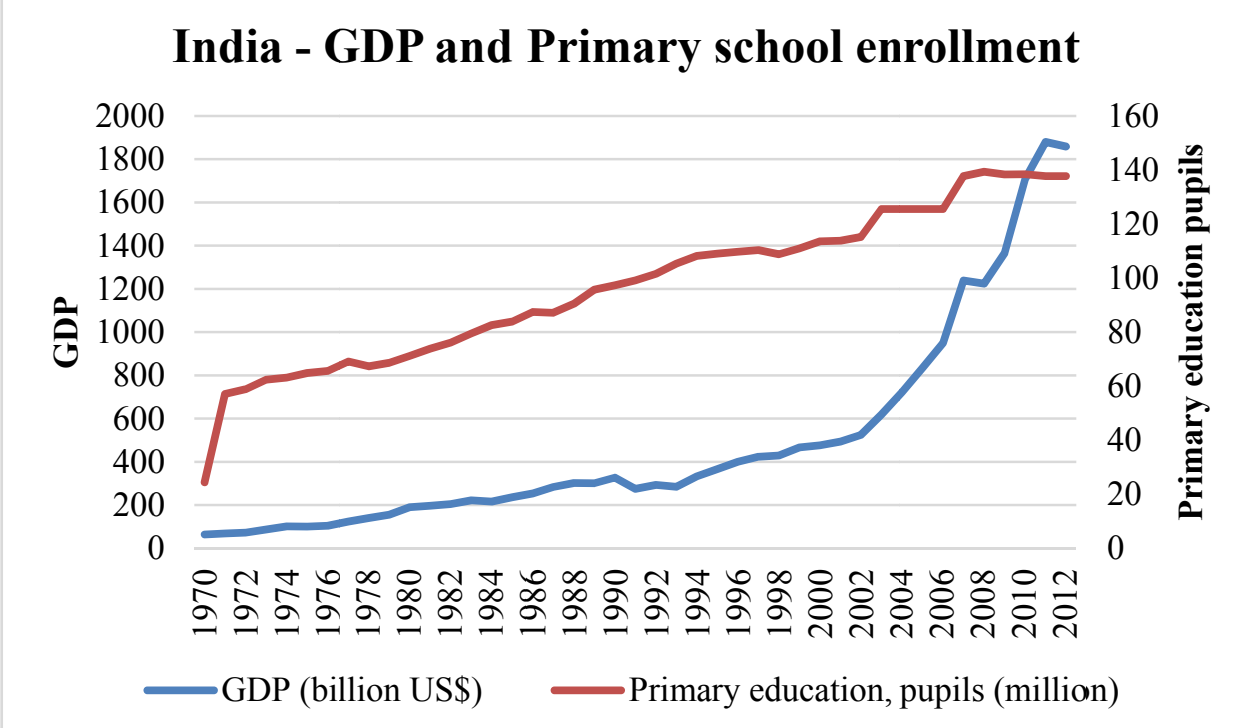

Figure 3. Movement of GDP and primary education pupil numbers from 1970-2012 in India

Figures 1, 2, and 3 outline the movement of GDP (in billion US\$) and total number of primary education pupils (million) from 1970-2012 in China, U.S, and India respectively. In case of China, a sustained growth in GDP can be clearly observed starting in the 1990's, which shows an exponential trend towards the next two decades of study. Primary education enrollment numbers on the other hand indicated a sharp declining trend starting in the late 1970s, slight increase in the mid 90s, and again a decline since 2000s to the present time. These changes could be attributed to the one child policy in China, formally instituted in the early 1980 s, which had a significant impact on the overall population growth rate of the country.

For the U.S, while GDP showed an increasing trend throughout the study period, primary education enrollment numbers showed a stable trend with slight fluctuations over a few time periods indicating overall stability in the number of primary education enrollments in the country during the study period of 1970-2012.

In case of India, both GDP and primary education enrollment numbers followed an increasing trend throughout the study period. The continued increase in primary education enrollment numbers in India could be attributed to various initiatives started by the central and state governments in the past few decades aimed at expanding primary education.

The model used for estimation was ordinary least square (OLS) for the entire dataset as well as for the individual country regressions. The equation estimated is mentioned below:

$$
\begin{aligned}
& \text { Ln GDP } P_{i}=\beta 1+\beta 2 \text { Ln Grad Age Pop Female }+\beta 3 \text { Ln Grad Age Pop Male }+\beta 4 \text { Mortality rate }+ \\
& \beta 5 \text { Ln Prim Edu Pupils }+\beta 6 \text { School Enroll Prim }+\beta 7 \text { Popn ages } 0-14+\varepsilon_{i}
\end{aligned}
$$

where $\operatorname{Ln} G D P_{i}$ is the natural log of GDP market prices (current US\$), which is the sum of gross value added by all resident producers in the economy plus any product taxes and minus any subsidies not included in the value of the products, Ln Grad Age Pop Female, and Ln 
Grad Age Pop Male are the respective natural log values of female and male population of the age-group theoretically corresponding to the primary school graduation age as indicated by theoretical entrance age and duration. Mortality rate is specifically the mortality rate under-5 (per 1,000) defined as the probability per 1,000 that a newborn baby will die before reaching age five, if subject to current age-specific mortality rates, Ln Prim Edu Pupils is the total number of pupils enrolled at primary level in public and private schools, School Enroll Prim (School enrollment, primary (\% gross)) is the total enrollment in primary education, regardless of age, expressed as a percentage of the population of official primary education age, Popn ages $0-14$ is the population between the ages 0 to 14 expressed as a percentage of the total population, and $\varepsilon_{i}$ is the error term. The above definitions for variables included in the model are defined by the World Bank (2014).

\section{Results}

The results of the OLS regression for all countries showed significant effects for all variables included in the model. Positive significant effects on GDP were observed for primary school graduation age population (male) and primary education pupils' population. Mortality rate under-5 (per 1,000), primary school graduation age population (female), population between the ages 0 to 14 as a percentage of the total population, and primary school enrollment ratio (\% of gross enrollment) showed significant negative impacts on GDP as a measure of economic growth for the countries of study. These results are presented in Table 2.

Table 2. Regression estimates for dataset including all countries of study to determine the impact of primary education and related variables on GDP as a measure of economic growth

\begin{tabular}{lcccc}
\hline Variable & Estimates & Std. Error & t Value & $\operatorname{Pr}>|\mathrm{t}|$ \\
\hline Intercept & 38.84137 & 1.54515 & 25.14 & $<.0001^{* * *}$ \\
Ln Grad Age Female Popn & -9.62905 & 2.97596 & -3.24 & $0.0016^{* * *}$ \\
Ln Grad Age Male Popn & 8.68664 & 2.92079 & 2.97 & $0.0035^{* * *}$ \\
Mortality rate & -0.00495 & 0.0026 & -1.9 & $0.0591^{*}$ \\
Ln Prim Edu Pupils Popn & 0.54622 & 0.30242 & 1.81 & $0.0734^{*}$ \\
School Enroll Prim (\% gross) & -0.02162 & 0.00581 & -3.72 & $0.0003^{* * *}$ \\
Popn ages 0-14 (\% total) & -0.15205 & 0.01912 & -7.95 & $<.0001^{* * *}$ \\
\hline
\end{tabular}

$\mathrm{R}$-square $=0.9197(*$ significant at $0.10, * *$ significant at $0.05, * * *$ significant at 0.01 alpha levels).

Differences were observed among individual country regressions for the impact of study variables on GDP as a measure of economic growth (Table 3). In the case of China, significant positive effects were observed for primary school graduation age population (male) and primary education pupils' population. Negative significant impacts were observed for primary school graduation age population (female), population between the ages 0 to 14 as a percentage of the total population, and primary school enrollment ratio $(\%$ of gross 
enrollment). Mortality rate did not show statistical significance in the case of China however the sign of the parameter estimate was negative.

Table 3. Regression estimates for China to determine the impact of primary education and related variables on GDP as a measure of economic growth

\begin{tabular}{lcccc}
\hline Variable & Estimates & Std. Error & $\mathrm{t}$ Value & $\operatorname{Pr}>|\mathrm{t}|$ \\
\hline Intercept & 4.56061 & 15.36318 & 0.3 & 0.7683 \\
Ln Grad Age Female Popn & -14.911 & 1.92933 & -7.73 & $<.0001^{* * *}$ \\
Ln Grad Age Male Popn & 12.65783 & 1.86262 & 6.8 & $<.0001^{* * *}$ \\
Mortality rate & -0.0038 & 0.01081 & -0.35 & 0.727 \\
Ln Prim Edu Pupils Popn & 3.44818 & 1.07728 & 3.2 & $0.0029 * * *$ \\
School Enroll Prim (\% gross) & -0.01618 & 0.00473 & -3.42 & $0.0016^{* * *}$ \\
Popn ages 0-14 (\% total) & -0.15053 & 0.04177 & -3.6 & $0.0009^{* * *}$ \\
\hline
\end{tabular}

$\mathrm{R}$-square $=0.9811(*$ significant at $0.10, * *$ significant at $0.05, * * *$ significant at 0.01 alpha levels)

For the U.S, very few variables showed statistical significance for the impact on GDP as a measure of economic growth (Table 4). Mortality rate showed a highly significant negative impact on GDP, as well as a significant negative impact on GDP was observed for population between the ages 0 to 14 as a percentage of the total population. Again, the sign of the parameter estimate was negative for primary school graduation age population (female), although no statistical significance was observed for both male and female primary school graduation age populations.

Table 4. Regression estimates for U.S determine the impact of primary education and related variables on GDP as a measure of economic growth

\begin{tabular}{lcccc}
\hline Variable & Estimates & Std. Error & $\mathrm{t}$ Value & $\operatorname{Pr}>|\mathrm{t}|$ \\
\hline Intercept & 3.33025 & 5.21988 & 0.64 & 0.5275 \\
Ln Grad Age Female Popn & -8.72304 & 8.11489 & -1.07 & 0.2896 \\
Ln Grad Age Male Popn & 10.55011 & 8.2119 & 1.28 & 0.2071 \\
Mortality rate & -0.11727 & 0.02374 & -4.94 & $<.0001^{* * *}$ \\
Ln Prim Edu Pupils Popn & 0.16915 & 0.33891 & 0.5 & 0.6207 \\
School Enroll Prim (\% gross) & 0.00122 & 0.01234 & 0.1 & 0.9219 \\
Popn ages 0-14 (\% total) & -0.11202 & 0.04268 & -2.62 & $0.0126^{* *}$ \\
\hline
\end{tabular}

$\mathrm{R}$-square $=0.9876(*$ significant at $0.10, * *$ significant at $0.05, * * *$ significant at 0.01 alpha levels) 
The country specific regression for India revealed statistical significance for all variables except for primary school enrollment ratio (\% of gross enrollment), as recorded in Table 5. Significant positive effects were observed for primary school graduation age population (female), and primary education pupils' population. This result confirms the findings from previous studies that discussed in the literature section, that suggest higher and positive returns from investment in female education as compared to males. Negative significant impacts on GDP were observed for primary school graduation age population (male), population between the ages 0 to 14 as a percentage of the total population, and mortality rate.

Table 5. Regression estimates for India determine the impact of primary education and related variables on GDP as a measure of economic growth

\begin{tabular}{lcccc}
\hline Variable & Estimates & Std. Error & $\mathrm{t}$ Value & $\operatorname{Pr}>|\mathrm{t}|$ \\
\hline Intercept & 185.4904 & 18.88414 & 9.82 & $<.0001^{* * *}$ \\
Ln Grad Age Female Popn & 21.42796 & 7.1873 & 2.98 & $0.0051^{* * *}$ \\
Ln Grad Age Male Popn & -30.8878 & 7.70209 & -4.01 & $0.0003^{* * *}$ \\
Mortality rate & -0.04606 & 0.00594 & -7.76 & $<.0001^{* * *}$ \\
Ln Prim Edu Pupils Popn & 0.33743 & 0.14716 & 2.29 & $0.0278^{* *}$ \\
School Enroll Prim (\% gross) & 0.00131 & 0.00492 & 0.27 & 0.7919 \\
Popn ages 0-14 (\% total) & -0.13787 & 0.0554 & -2.49 & $0.0176^{* *}$ \\
\hline
\end{tabular}

R-square $=0.9914(*$ significant at $0.10, * *$ significant at $0.05, * * *$ significant at 0.01 alpha levels)

\section{Conclusions and Recommendations}

Early education is considered as a significant source of economic growth due to its contribution toward individual empowerment and development of human capital. It is particularly recognized as a crucial factor in countries with high populations, as well as those witnessing rapid economic growth. The purpose of this study was to understand how the relationship between primary education and economic growth varied between China, India, and the U.S, the top three populous nations in the world and to investigate for plausible reasons leading to the differences observed among these countries.

Several inferences can be drawn from the analysis of the dataset for the three countries. In all of the study countries characterized by high populations, an increase in the number of students enrolled in primary education positively impacted economic growth which supports the hypothesis that formed the basis of this study. This result supports the need for policy measures for enhancing and expanding primary education initiatives in these countries. Mortality rate impacting economic growth negatively was an obvious result indicating the importance of higher availability of workable population that will contribute to increase in GDP. 


\section{MlMacrothink}

International Research in Education

ISSN 2327-5499

2016, Vol. 4, No. 1

The negative impact of primary graduation age population (female) is the most introspective result. This factor has not been explained concretely so far in previous studies. In contrast to the results for the study in hand, this effect has shown statistical insignificance in one of the recent studies by Barro (2013) as discussed in the literature review, and therefore demands further exploration.

Gender related differences in primary education graduating population can be attributed to varied differences in the cultural and social systems between the study countries. These differences were more evident when examining the results of individual country regressions. For example both male and female primary education graduation age population showed no statistical significance on economic growth in the U.S, while for China and India the effects on economic growth were significant with clearly outlined gender related differences in primary education graduation age population. This could possibly be attributed to the fact that countries such as the US have already made significant progress in gender equality, in comparison to India and China. Additionally, gender based differences regarding the type of jobs available for males and females based on their respective education levels could also have vastly different implications for economic growth in the developing versus developed economies.

Finally, high percentages of younger population in the age group of 0-14 years, as well as higher enrollment ratio in primary schools as percentage of gross enrollment negatively impacting economic growth can be attributed to the low availability of productive population that could possibly contribute to increase in GDP.

In conclusion, the results from this analysis highlight the influence of primary education as well as gender related differences in primary education and their corresponding impacts on the growth of these vigorous economies. This study can form the foundation for further research on how the accumulation of human capital through education in these countries will impact the geographical concentration of global economic power in the future.

\section{References}

Barro, R. J., \& Sala-i-Martin, X. (1995). Economic Growth. New York: MicGraw- Hill.

Barro, R. J. (2001). Human Capital and Growth. American Economic Review, 91(2), 12-17. http://dx.doi.org/10.1257/aer.91.2.12

Barro R. J. (2013). Education and Economic Growth. Annals of Economics and Finance, 14, 301-328.

Behrman, J., Foster, A. D., Rosenzweig, M. R., \& Vashishtha, P. (1999). Women's Schooling, Home Teaching, and Economic Growth. The Journal of Political Economy, 107(4), 682-714. http://dx.doi.org/10.1086/250075

Easterly, W. (2001). The Elusive Quest for Growth: Economists' Adventures and Misadventures in the Tropics. Cambridge, USA: MIT Press. 


\section{Macrothink}

International Research in Education

ISSN 2327-5499

2016, Vol. 4, No. 1

Grossman, G., \& Helpman, E. (1991). Innovation and Growth in the Global Economy. Cambridge, USA: MIT Press.

Loening, J. L. (2005). Effects of Primary, Secondary, and Tertiary Education on Economic Growth (p. 75). World Bank Publications. http://dx.doi.org/10.2139/ssrn.753647

Mankiw, N. G., Romer, D., \& Weil, D. N. (1992). A Contribution to the Empirics of Economic Growth. Quarterly Journal of Economics, 107(2), 407-437. http://dx.doi.org/10.2307/2118477

National Intelligence Council of the U.S. Global Trends 2030: Alternative Worlds. (2012).

Petrakis, P. E., \& Stamatakis, D. (2002). Growth and Educational Levels: A Comparative Analysis. Economics of Education Review, 21, 513-521. http://dx.doi.org/10.1016/S0272-7757(01)00050-4

Pritchett, L. (2001). Where Has All the Education Gone? World Bank Economic Review, 15(3), 367-391. http://dx.doi.org/10.1093/wber/15.3.367

Psacharopoulos, G. (1994). Returns to Investment in Education: A Global Update. World Development, 22(9), 1325-1343. http://dx.doi.org/10.1016/0305-750X(94)90007-8

Romer, P. M. (1990). Endogenous Technical Change. Journal of Political Economy, 98(5), S71-S102. http://dx.doi.org/10.1086/261725

Sianesi, B., \& Van Reenen, J. (2003). The returns to education: macroeconomics. Journal of Economic Surveys, 17(2), 157-200. http://dx.doi.org/10.1111/1467-6419.00192

Sala-i-Martin, X. (2002). 15 Years of New Growth Economics: What Have We Learnt? Discussion Paper, pp. 102-47, Department of Economics, Columbia University.

Solow, R. M. (1956). A Contribution to the Theory of Economic Growth. Quarterly Journal of Economics, 70(1), 65-94. http://dx.doi.org/10.2307/1884513

World Bank. (2014). Education Statistics of the World Bank. Retrieved September 15, 2014, from http://data.worldbank.org/data-catalog/ed-stats

\section{Copyright Disclaimer}

Copyright reserved by the authors.

This article is an open-access article distributed under the terms and conditions of the Creative Commons Attribution license (http://creativecommons.org/licenses/by/3.0/). 